\title{
Response of blood gas tensions to aminophylline and isoprenaline in patients with asthma ${ }^{1}$
}

\author{
E. TAI AND JOHN READ \\ From the Department of Medicine, University of Sydney, Sydney, Australia
}

\begin{abstract}
Aminophylline and isoprenaline, two drugs widely used in the management of asthma, have a pulmonary vasodilator action as well as a bronchodilator action. If regional pulmonary vasoconstriction in poorly ventilated parts of the lungs is a significant compensatory phenomenon in asthma, the effects of administration of these agents on gas exchange would depend on the relative magnitudes of bronchodilator action and pulmonary vasodilator action in the individual patient. If vasodilator action were greater than bronchodilator action in significant portions of the lungs, maldistribution of ventilation-blood flow ratios would increase and arterial oxygen tension might fall. In 40 patients with chronic asthma, arterial blood gas tensions, minute ventilation, alveolar-arterial oxygen tension gradient, physiological dead space/tidal volume ratio, and oxygen consumption were measured before and at intervals up to 20 to 40 minutes after the administration of various agents: in 13 patients, $250 \mathrm{mg}$. of aminophylline intravenously; in 16 patients, six deep inhalations of $1 \%$ isoprenaline aerosol; in 11 patients, after various control procedures. There were no significant changes following the control procedures. Administration of both aminophylline and isoprenaline was followed by increases of F.E.V. $\cdot_{1 \cdot 0}$ and increases of minute ventilation. Despite these changes, five patients in each group showed a fall of arterial $\mathrm{Po}_{2}$ of $5 \mathrm{~mm}$. $\mathrm{Hg}$ or more. This was accompanied by an increase of alveolar-arterial oxygen tension gradient. It was concluded that the decreases of arterial blood $\mathrm{Po}_{2}$ resulted from reversal of pre-existing, compensatory, regional pulmonary vasoconstriction by the pulmonary vasodilator action of each drug in some subjects.
\end{abstract}

\begin{abstract}
A fall of arterial oxygen tension or saturation has been demonstrated in some patients with irreversible chronic airflow obstruction following intravenous injection of aminophylline (Halmagyi and Cotes, 1959; Daly and Howard, 1965; Pain, Charlton, and Read, 1967). The most likely mechanism of this phenomenon is reversal of preexisting vasoconstriction in poorly ventilated alveolar populations by the pulmonary vasodilator action of the drug. Aminophylline is widely used in the treatment of bronchial asthma, but in patients with this disorder one might expect the bronchodilator action of the drug to outweigh any effects of its pulmonary vasodilator action. Following injection of aminophylline in patients with asthma, arterial oxygen tension might be expected to rise if it were originally reduced.
\end{abstract}

1Supported by a research fellowship and a erant-in-aid from the Asthma Foundation of New South Wales and a grant-in-aid from the National Heart Foundation of Australia
Isoprenaline shares with aminophylline the capacity to act both as a bronchodilator and as a pulmonary vasodilator. There is, however, a remarkable absence of data on the response of arterial blood gas tensions to the administration of aminophylline, isoprenaline, or other bronchodilator agents. The present paper reports detailed studies of blood gas tensions and other variables in 40 patients with bronchial asthma following intravenous aminophylline, inhaled isoprenaline, or an appropriate control procedure.

\section{MATERIALS AND METHODS}

The subjects of the present study ranged in age from 17 to 68 years (mean 43 years). All suffered from chronic asthma, which had been present for periods ranging from one year to most of their lives. The diagnosis was based on an appropriate clinical history and on the demonstration on a number of occasions of the presence of reversible airways obstruction by measurement of vital capacity (V.C.) 
and forced expiratory volume in one second (F.E.V.1.0) before and after bronchodilator administration. Some subjects had some residual fixed airways obstruction even at their best, but in each case asthma was the major cause of long-term disability. The severity of the asthma at the time of the present studies varied considerably among the different subjects, but none was acutely ill. Data concerning F.E.V.1.0 and blood gas tensions at the time of the study are given in Table I.

T A B L E I

INITIAL F.E.V.1.0 VALUES AND BLOOD GAS TENSIONS

\begin{tabular}{|c|c|c|c|c|}
\hline & 'Saline' & 'Blank' & $\begin{array}{l}\text { Aminophyl- } \\
\text { line }\end{array}$ & $\begin{array}{c}\text { Isoprena- } \\
\text { line }\end{array}$ \\
\hline No. & 5 & 6 & 13 & 16 \\
\hline $\begin{array}{lc}\text { F.E.V.1.0 } & (\%) \\
\text { Mean } & \cdots \\
\text { S.D. } & \cdots \\
\text { Range } & \cdots \\
\end{array}$ & $\begin{array}{c}47 \cdot 0 \\
30 \cdot 2 \\
17-92 \\
\end{array}$ & $\begin{array}{c}57 \cdot 6 \\
24 \cdot 8 \\
23-87 \\
\end{array}$ & $\begin{array}{c}44 \cdot 6 \\
24 \cdot 2 \\
27-100 \\
\end{array}$ & $\begin{array}{c}40 \cdot 8 \\
17 \cdot 7 \\
19-72 \\
\end{array}$ \\
\hline $\begin{array}{cc}\mathrm{Po}_{2}(\mathrm{~mm} . \mathrm{Hg}) \\
\text { Mean } & \cdots \\
\text { S.D. } & \cdots \\
\text { Range } & \cdots\end{array}$ & $\begin{array}{c}69 \cdot 4 \\
15 \cdot 1 \\
50-87\end{array}$ & $\begin{array}{c}72 \cdot 7 \\
6 \cdot 0 \\
65-81\end{array}$ & $\begin{array}{c}69 \cdot 9 \\
11 \cdot 5 \\
54-85\end{array}$ & $\begin{array}{c}66 \cdot 9 \\
10 \cdot 5 \\
52-90\end{array}$ \\
\hline $\begin{array}{cc}\mathrm{PCO}_{2}(\mathrm{~mm} . \mathrm{Hg}) \\
\text { Mean } & \ldots \\
\text { S.D. } & \ldots \\
\text { Range } & \ldots\end{array}$ & $\begin{array}{c}43 \cdot 0 \\
4 \cdot 9 \\
39-51\end{array}$ & $\begin{array}{c}36 \cdot 5 \\
4 \cdot 4 \\
32-42\end{array}$ & $\begin{array}{c}41 \cdot 9 \\
5 \cdot 5 \\
35-55\end{array}$ & $\begin{array}{c}39 \cdot 9 \\
4 \cdot 4 \\
31-48\end{array}$ \\
\hline
\end{tabular}

Those patients receiving long-term corticosteroid therapy continued their usual drug dosage on the day of study. Any oral bronchodilator therapy was omitted on the morning of the study, and no aerosol therapy was given in the three hours before the tests were carried out.

Subjects came to the laboratory in the morning and V.C. and F.E.V.1.0 were measured by standard methods. The subject then rested on a cardiac bed with its head inclined at $45^{\circ}$ to the horizontal, and percutaneous brachial artery puncture was performed with a Riley needle. He then breathed air from a Tissot spirometer via a mouthpiece and one-wayvalve system. Expired gas was collected in Douglas bags and arterial blood was withdrawn into syringes over 2-minute intervals as required.

The detailed protocols for aminophylline and isoprenaline studies are shown in Table II. In summary, after all preliminary procedures had been completed, the subject breathed from the Tissot spirometer circuit throughout the remainder of the experiment (except for the period of isoprenaline inhalation). After an initial period of 5 minutes to enable the subject to become accustomed to breathing from the circuit, two 2-minute control collections of expired gas and arterial blood were made during the next 10 minutes. The drug in question was then administered: in 13 patients $250 \mathrm{mg}$. of aminophylline was given intravenously through a fine hypodermic needle in $10 \mathrm{ml}$. of solution over 3 minutes; 16 other patients took six deep inhalations of an aerosol of $1 \%$ isoprenaline generated from a
T A B L E I I

PROTOCOL FOR AMINOPHYLLINE AND ISOPRENALINE STUDIES

\begin{tabular}{|c|c|}
\hline Time (min.) & Procedure \\
\hline $\begin{array}{l}-10 \\
-5 \\
0 \\
2-3 \\
8-9 \\
11 \\
14-15 \\
16-17 \\
18-19 \\
20-21\end{array}$ & $\begin{array}{l}\text { Measure V.C. and F.E.V.1.0 } \\
\text { Begin breathing on Tissot circuit } \\
\text { Begin recording ventilation on Tissot chart } \\
\text { Blood and gas sample collection } 1 \\
\text { Blood and gas sample collection } 2 \\
\text { Begin administering test agent } \\
\text { Blood and gas sample collection } 3 \\
\text { Blood and gas sample collection } 4 \\
\text { Blood and gas sample collection } 5 \\
\text { Blood and gas sample collection } 6\end{array}$ \\
\hline $\begin{array}{c}24-25 \\
29-30 \\
32\end{array}$ & $\left.\begin{array}{l}\text { Blood and gas sample collection } 7 \\
\text { Blood and gas sample collection } 8 \\
\text { Measure V.C. and F.E.V.1.0 }\end{array}\right\}$ (Isoprenaline) \\
\hline $\begin{array}{c}40-41 \\
50-51 \\
53\end{array}$ & $\left.\begin{array}{l}\text { Blood and gas sample collection } 7 \\
\text { Blood and gas sample collection } 8 \\
\text { Measure V.C. and F.E.V.1.0 }\end{array}\right\} \begin{array}{c}\text { (Aminophyl- } \\
\text { line) }\end{array}$ \\
\hline
\end{tabular}

De Vilbiss No. 40 hand nebulizer. A further six samples of expired gas and arterial blood were collected over the succeeding 20 to 40 minutes at the times shown in Table II. Measurements of V.C. and F.E.V.1.0 were repeated at the end of the experiment.

Eleven additional control experiments were performed. The procedure outlined above and in Table II was followed, except that in five patients ('saline studies') $10 \mathrm{ml}$. of normal saline was injected instead of aminophylline ; and in six others ('blank studies'), no isoprenaline was put in the nebulizer but six deep inhalations were made as before.

Oxygen tension in arterial blood samples $\left(\mathrm{Po}_{2}\right)$ was measured with a polarographic electrode, and carbon dioxide tension $\left(\mathrm{PCO}_{2}\right)$ with a Severinghaus electrode, both at $37 \pm 0 \cdot 1^{\circ} \mathrm{C}$., with adequate calibration procedures. Minute ventilation $\left(\dot{\mathbf{V}}_{E}\right)$ was measured from the volumes of expired gas collected, and corrected to B.T.P.S. conditions. Oxygen and $\mathrm{CO}_{2}$ concentrations in mixed expired gas were measured by Haldane $\delta$ analysis or with a respiratory mass spectrometer, and oxygen consumption $\left(\hat{V}_{O_{2}}\right)$ was calculated. $V_{\mathbf{D}} / V_{\mathbf{T}} \circ$ ratio (ratio of physiological dead space to tidal volume) was derived from arterial and mixed expired $\frac{7}{0}$ $\mathrm{PCO}_{2}$ values; it was not corrected for apparatus dead space $\left(70 \mathrm{ml}\right.$.), since we were concerned with changes $N_{0}$ of $V_{D} / V_{T}$ ratio as a result of drug action. Alveolararterial oxygen tension gradients $\left(\mathrm{A}-\mathrm{a} \mathrm{O}_{2}\right)$ were $\stackrel{N}{\mathrm{O}}$ obtained from measured $\mathrm{Po}_{2}$ and alveolar $\mathrm{Po}_{2} \underset{\mathrm{N}}{\mathrm{N}}$ derived from the alveolar air equation. Normal pre- 0 dicted F.E.V.1.0 for each subject was taken to be $70 \%$ of the V.C. value predicted from the data of Needham, Rogan, and McDonald (1954); and $\stackrel{\oplus}{\Phi}$ measured values of F.E.V.1.0 were expressed as a percentage (F.E.V.1.0\%) of the F.E.V.1.0 predicted in $T$ this way. The Tissot spirometer chart provided a continuous record of respiratory rate and tidal volume except for brief periods when the spirometer $\stackrel{\mathbb{D}}{\mathbb{D}}$ was being refilled with air. 
RESULTS

In considering changes following the administration of a drug or other procedure, the second set of control values has been arbitrarily taken as the standard of comparison. Increases or decreases from this set of measurements are referred to in the text or illustrated in the Figures. With eight sets of measurements of up to seven variables from each of 40 subjects available, it is clearly not possible to present all the individual data; and they have been grouped in various ways in the description that follows.

Figure 1 shows mean values of the variables studied at each of the eight time intervals defined for the four experimental groups. Patients in the 'saline study' group showed only a small mean increase of $\dot{V}_{E}$ at the fourth measurement and some instability of $\mathbf{V o}_{2}$. Patients in the 'blank study' group showed some final fall of $\dot{V}_{E}$ and of A-a $\mathrm{O}_{2}$, together with a fall in mean F.E.V. ${ }_{\cdot \cdot \cdot 0}$ over the experiment. In these 11 control studies only one patient at one time interval showed a change of arterial $\mathrm{Po}_{2}$ of more than $4 \mathrm{~mm}$. $\mathrm{Hg}$ or a rise of $\mathrm{A}-\mathrm{a} \mathrm{O}_{2}$ of more than $5 \mathrm{~mm}$. $\mathrm{Hg}$.
Initial mean values for subjects in the aminophylline and isoprenaline groups were closely comparable for $\mathbf{P o}_{2}, \mathbf{P c o}_{2}, \mathrm{~V}_{\mathrm{D}} / \mathrm{V}_{\mathrm{T}}$ ratio, $\mathbf{V}_{\mathrm{E}}, \mathbf{V o}_{2}$, and F.E.V. ${ }_{\cdot 1 \cdot 0} \%$; but the isoprenaline group had a rather larger initial mean $\mathrm{A}-\mathrm{a} \mathrm{O}_{2}$ (39 compared with $33 \mathrm{~mm}$. Hg). Following the administration of each active drug there was a small decrease ( 2 to $3 \mathrm{~mm} . \mathrm{Hg}$ ) in both mean $\mathrm{Po}_{2}$ and mean $\mathrm{PcO}_{2}$, and a small increase $\left(4\right.$ to $6 \mathrm{~mm}$. $\mathrm{Hg}$ ) in mean $\mathrm{A}-\mathrm{a} \mathrm{O}_{2}$. There was a well-marked increase in mean ventilation, somewhat larger following aminophylline; and an increase in mean F.E.V..$_{1 \cdot 0} \%$, somewhat larger following isoprenaline. The increase in ventilation resulted largely from an increase in tidal volume, the increase in respiratory rate being relatively small. In terms of mean values then, one would remark on an increase in F.E.V.V. ${ }_{1 \cdot 0} \%$ and in ventilation, a small increase in $\mathrm{A}-\mathrm{a} \mathrm{O}_{2}$, and minor changes only in blood gas tensions.

However, though the mean blood gas tension changes were not impressive, individual subjects in both groups given an active drug did show larger changes, especially in arterial $\mathbf{P o}_{2}$. Figure 2 illustrates this point. Subjects in each drug group were divided into three sub-groups: I, those show-

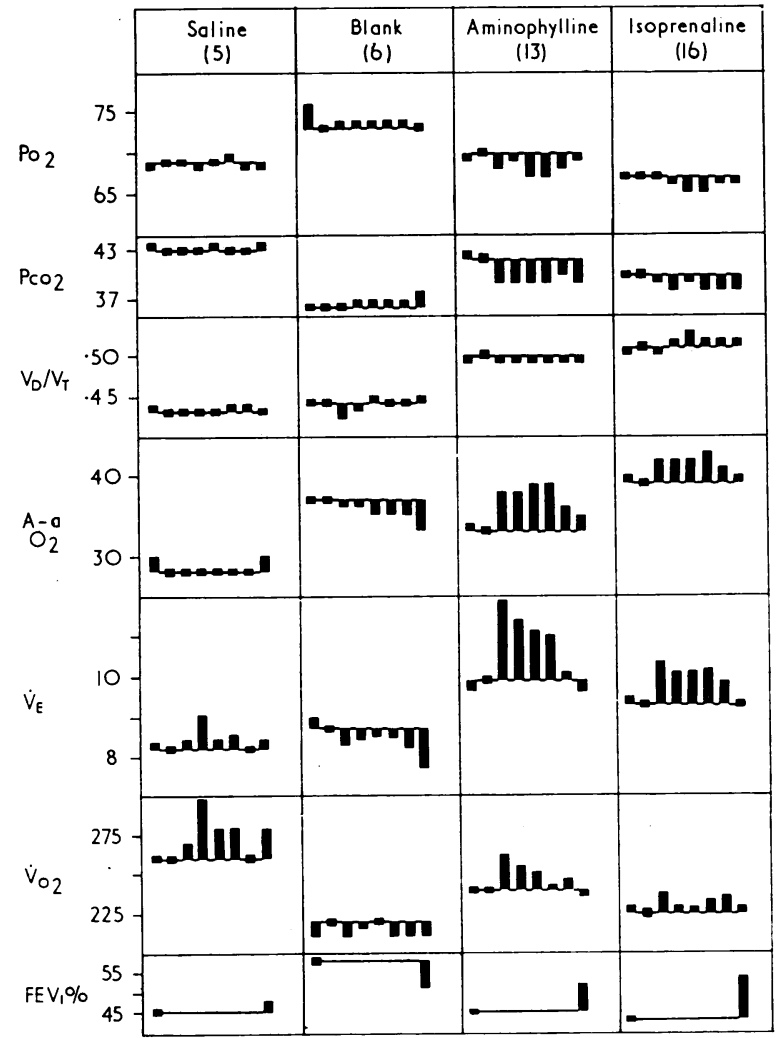

FIG. 1. Mean values of a number of variables at each of eight time intervals defined in Table II. The number of patients in each group is shown at the top of each column. The first two values are control values, and the next six follow at defined intervals after a drug or control procedure. The horizontal lines pass through the second control values. Abbreviations: arterial oxygen tension $\left(\mathrm{PO}_{2}, \mathrm{~mm} . \mathrm{Hg}\right)$; arterial carbon dioxide tension $\left(\mathrm{PCO}_{2}, \mathrm{~mm} . \mathrm{Hg}\right)$; physiological dead space/tidal volume ratio $(V \mathrm{D} / V \mathrm{~T})$; alveolar-arterial oxygen tension gradient $\left(\mathrm{A}-\mathrm{a} \mathrm{O}_{2}, \mathrm{~mm} . \mathrm{Hg}\right)$; minute ventilation ( $\dot{V} \mathrm{E}$, litres per minute); oxygen consumption ( $\dot{\mathrm{O}}_{2}$, ml. per minute); F.E.V.1.0 as a percentage of predicted F.E.V.1.0 $\left(F . E . V_{\cdot 1 \cdot 0} \%\right)$. 


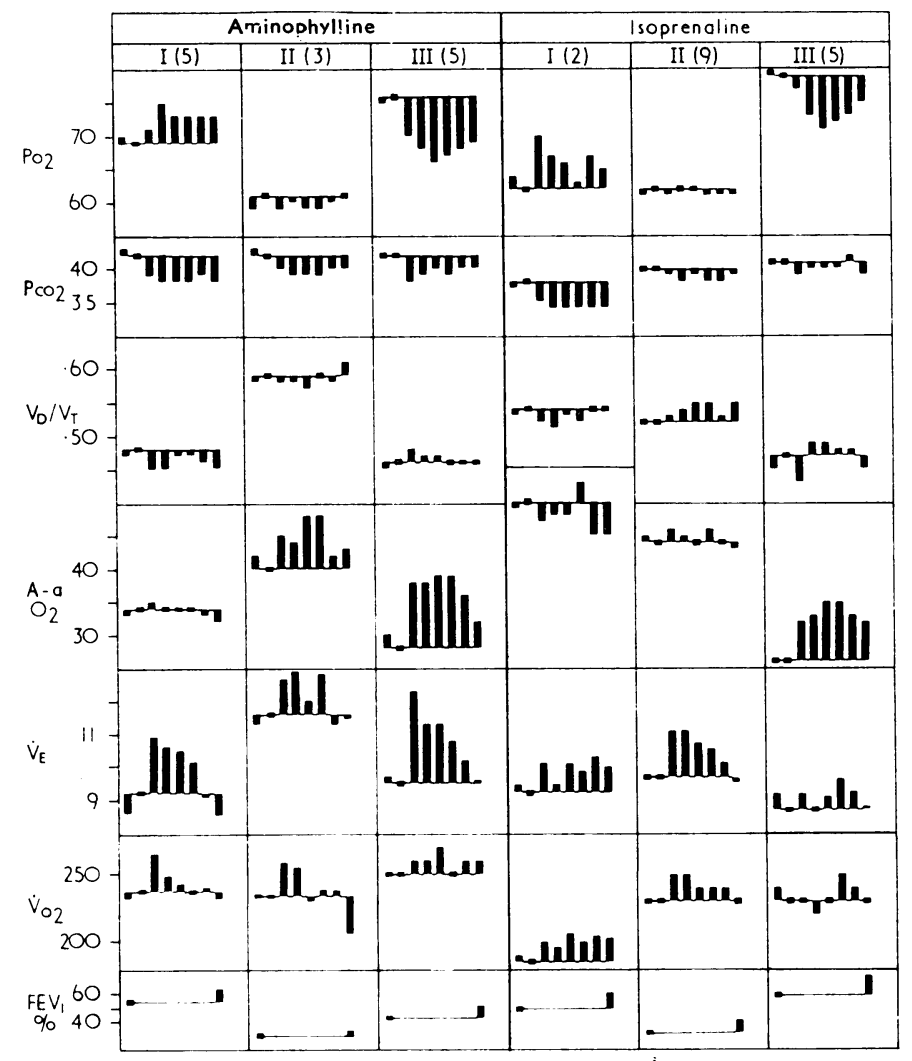

FIG. 2. Mean values of a number of variables at each of eight time intervals $\mathrm{N}$ defined in Table II. Conventions as for o Figure 1. The patients in each drug or group have been subdivided (in the $\vec{\omega}$ fashion $d$ scribcd in the text) into those 음 showing (I) an increase, (II) no change, or (III) a decrease in arterial $\mathrm{P}_{\mathrm{O}_{2}}$ following $\mathrm{Z}$ drug administration.

ing an increase of arterial $\mathrm{Po}_{2}$ of at least $5 \mathrm{~mm} . \mathrm{Hg}$ in at least two post-drug measurements ; II, those showing no change of $\mathrm{Po}_{2}$ as great as $5 \mathrm{~mm}$. $\mathrm{Hg}$ at any time ; III, those showing a fall of $\mathrm{Po}_{2}$ of at least $5 \mathrm{~mm} . \mathrm{Hg}$ in at least two of the post-drug values. In no patient did a change of $5 \mathrm{~mm}$. $\mathrm{Hg}$ of $\mathrm{Po}_{2}$ occur as a single isolated observation, so that these groups cover all cases. Mean values for the remaining measurements in these sub-groups were then calculated and are shown in Figure 2.

Among 13 patients given aminophylline, five showed an increase, five a decrease, and three no change in arterial $\mathrm{Po}_{2}$, using the limits defined above. The greatest mean increase was $6 \mathrm{~mm}$. $\mathrm{Hg}$, and the greatest mean decrease $10 \mathrm{~mm}$. $\mathrm{Hg}$. The largest individual increase of $\mathrm{Po}_{2}$ was $10 \mathrm{~mm} . \mathrm{Hg}$ and the largest individual decrease $19 \mathrm{~mm}$. $\mathrm{Hg}$. Among the 16 patients who received isoprenaline, two showed an increase, five a decrease, and nine no change in arterial $\mathrm{Po}_{2}$; with greatest mean increases and decreases both of $8 \mathrm{~mm}$. $\mathrm{Hg}$. The largest individual increases and decreases of $\mathrm{Po}_{2}$ in this group were 8 and $11 \mathrm{~mm}$. $\mathrm{Hg}$. Those patients in both drug groups who showed a fall of arterial $\mathrm{Po}_{2}$ had considerable increases of $\mathrm{A}-\mathrm{a} \mathrm{O}_{2}$ 음 (up to mean values of $11 \mathrm{~mm}$. $\mathrm{Hg}$ ), as did the sub- $\underset{x}{x}$ group showing no change of arterial $\mathrm{Po}_{2}$ after aminophylline. The remaining distinctions in Fig. 2 will be taken up in the Discussion.

In order to examine factors associated with the common increase in $\mathrm{A}-\mathrm{a} \mathrm{O}_{2}$, the data shown in $\frac{\mathrm{O}}{3}$ Fig. 3 were extracted. Attention was confined to $\rightarrow$ two measurements, the second (control) and the fifth (usually maximum deviation) in all subjects. N Each drug group was divided into two sub-groups:$\mathrm{A}$, those showing an increase of $\mathrm{A}-\mathrm{a} \mathrm{O}_{2}$ of $5 \mathrm{~mm}$. $\mathrm{Hg}$ or more between the second and fifth measure- $\omega$ ments; B, those not showing such an increase. The corresponding mean values for the othere variables were then calculated and are shown in Fig. 3. The mean increase of $\mathrm{A}-\mathrm{a} \mathrm{O}_{2}$ among those? in the aminophylline group showing any defined increase was $13 \mathrm{~mm}$. $\mathrm{Hg}$ (largest individual increase $19 \mathrm{~mm}$. $\mathrm{Hg}$ ); among those in the isopren-尺 aline group, $10 \mathrm{~mm} . \mathrm{Hg}$ (largest individual increase $\stackrel{\mathbb{Q}}{\Omega}$ $17 \mathrm{~mm} . \mathrm{Hg}$ ). In each drug group, the sub-group 


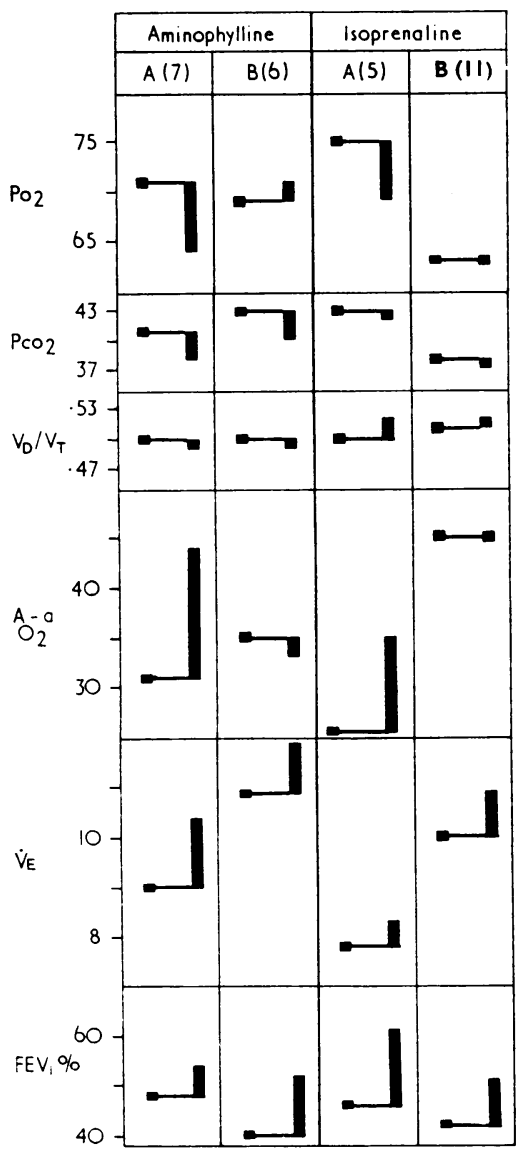

FIG. 3. Mean values of a number of variables at the second and fifth measurements defined in Table II. Conventions as for Figure 1. The patients in each drug group have been subdivided (in the fashion described in the text) into those showing $(A)$ an increase, or $(B)$ no increase in alveolararterial oxygen tension gradient following drug administration.

showing an increase in $\mathrm{A}-\mathrm{a} \mathrm{O}_{2}$ had a fall (mean of 6 to $7 \mathrm{~mm}$. $\mathrm{Hg}$ ) of arterial $\mathrm{Po}_{2}$; the remaining patients in each drug group showed no such change of arterial $\mathrm{Po}_{2}$.

\section{DISCUSSION}

Though mean changes in blood gas tensions for the groups of patients given aminophylline or isoprenaline as a whole were very small, individual changes were sometimes marked. Changes in arterial $\mathrm{PCO}_{2}$ were small and generally reflected the changes of $V_{E}$ which were common after both drugs. Changes in arterial $\mathrm{Po}_{2}$ were sometimes large and merit closer examination.
An obvious point is that, at different initial levels of $\mathrm{Po}_{2}$, a given change of arterial oxygen saturation $\left(\mathrm{SO}_{2}\right)$ may be associated with quite different absolute changes in arterial $\mathrm{Po}_{2}$. At high initial levels of $\mathrm{Po}_{2}$, quite a small decrease of $\mathrm{So}_{2}$ may be associated with a large decrease of $\mathrm{Po}_{2}$. Again, a decrease of arterial $\mathbf{P C O}_{2}$ (due to hyperventilation) will shift the haemoglobin-oxygen dissociation curve to the left, so that $\mathrm{Po}_{2}$ may decrease without any change in $\mathrm{So}_{2}$. To take both of these factors into account, the mean arterial oxygen saturations corresponding to the mean $\mathrm{Po}_{2}$ and $\mathrm{PCO}_{2}$ values shown in the first two rows of Fig. 2 were derived. In the two 'unchanged' (II) groups, $\mathrm{So}_{2}$ did not change significantly. In the 'changing' groups (I and III) the mean increases and decreases of $\mathrm{Po}_{2}$ corresponded to changes of about $2 \%$ in $\mathrm{So}_{2}$. Among individual subjects, the greatest falls of $\mathrm{So}_{2}$ following either drug were of the order of $5 \%$. The falls of $\mathrm{Po}_{2}$ reported in a number of patients therefore represent a genuine decrease in the level of oxygenation of the arterial blood. At the same time it should be emphasized that the groups showing a decrease of $\mathrm{Po}_{2}$ had relatively high initial mean arterial $\mathrm{Po}_{2}$ values of 76 and $79 \mathrm{~mm}$. $\mathrm{Hg}$, so that the tension changes have the effect of visually exaggerating the changes encountered.

That seven patients showed an increase of arterial $\mathrm{Po}_{2}$ following one or other of the drugs (Fig. 2) causes no surprise and calls for no further comment. Intuitively one might expect no other consequence than this following a lessening of airways obstruction (increase of F.E.V. .1 .0 ) and an increase in ventilation. That 10 patients (one-third of all subjects) should show a significant and sometimes large decrease of arterial $\mathrm{Po}_{2}$ in the face of comparable increases of F.E.V.$_{1 \cdot 0}$ and of ventilation is surprising and requires closer examination. The decreases of $\mathrm{Po}_{2}$ were not transient; they were apparent by the time of the first post-drug measurement, and they persisted to a diminishing extent through the final measurements, made 20 to 40 minutes after drug administration.

We may readily exclude most of the theoretically possible causes of a decrease in $\mathrm{Po}_{2}$. There was no systematic increase of $\mathrm{Vo}_{2}$ of sufficient magnitude to account for this phenomenon in some patients but not in others. Aminophylline has usually, and isoprenaline invariably, been shown to cause an increase rather than a decrease of cardiac output, so that a fall in total pulmonary blood flow cannot account for the decreases in arterial $\mathrm{Po}_{2}$. Nor can they be ascribed to diminu- 
tion in total or in 'alveolar' ventilation, for changes in these were in the opposite direction. Inspired oxygen tension did not change during the studies.

The only two remaining possibilities are increased maldistribution of ventilation-perfusion ratios and increased right-to-left shunting of blood. New anatomical right-to-left shunting channels have not been demonstrated (or even seriously postulated) in patients with asthma; and we are left with increased maldistribution of ventilationperfusion ratios as the only reasonable explanation. (In this context, continued blood flow through temporarily unventilated lung is treated as an extreme example of ventilation-perfusion ratio maldistribution rather than as a case of right-toleft shunt. Though the situation may be argued to be compatible with either classification, the functional mechanisms involved and the natural history have much more in common with ventilation-perfusion ratio maldistribution than with anatomical right-to-left shunt channels.)

The increased ventilation-perfusion ratio maldistribution may result from increased maldistribution of ventilation, of blood flow, or from further non-concordant maldistribution of both.

Increased maldistribution of ventilation seems unlikely to be the essential cause. In each of the groups showing a decrease of arterial $\mathrm{Po}_{2}$, F.E.V. ${ }_{\cdot \cdot \cdot 0}$ increased significantly following the drug, so that overall airways resistance was reduced. If the greatest proportional improvement in airways resistance occurred in regions of the lung with the greatest initial obstruction, an improvement in the distribution of inspired air and a rise of $\mathrm{PO}_{2}$ would be expected. Greater proportional improvement in airways resistance in initially less obstructed regions could theoretically lead to a worsening of inspired air distribution. But, in the presence of the increased ventilation almost invariably seen after the drugs, it is hard to conceive of the initially less well ventilated alveolar populations receiving even less ventilation than before the drug was given. It is very unlikely that the increased ventilation following drug administration led per se to any worsening of ventilation distribution. It will be recalled that the pattern was one of increased tidal volume with little increase in respiratory rate-a pattern which would be expected to lead to an improvement rather than a deterioration in the distribution of ventilation (Read, 1958).

By a process of exclusion, a worsening of the distribution of pulmonary blood flow (in relation to ventilation) remains as the most likely cause of the decrease of arterial $\mathbf{P o}_{2}$. This mechanism is a perfectly reasonable one in its own right, for botke aminophylline and isoprenaline are established믈 pulmonary vasodilators as well as bronchodilators $\overline{\bar{s}}$ We suggest that, in 10 patients, their pulmonary vasodilator action was more effective than their bronchodilator action. We think that, at least in some subjects, compensatory pulmonary vasoconstriction occurs in regions of the lungs which $\vec{\omega}$ are poorly ventilated as a result of local airways obstruction. If the administration of amino $\vec{x}$

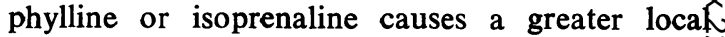
increase in blood flow (vasodilator action) than in ventilation (bronchodilator action) in such poorlye ventilated regions, the local ventilation-perfusion ratio will fall even further, and there will result 2 fall of arterial $\mathrm{Po}_{2}$. This phenomenon of reversaL of regional, compensatory vasoconstriction mus? have been of considerable magnitude in the 10 subjects in the two groups III of Fig. 2, since i $\stackrel{\mathbb{B}}{B}$ was sufficient to cause a decrease of arterial Po in the face of overall improvement in airways obstruction and of considerable increases of totab ventilation.

The increased $\mathrm{A}-\mathrm{a} \mathrm{O}_{2}$ seen in conjunction witl the falls of arterial $\mathrm{Po}_{2}$ (Figs 2 and 3) is consisten with the interpretation that the decreases of Po result from increased ventilation-perfusion ration maldistribution. The increased $\mathrm{A}-\mathrm{a} \mathrm{O}_{2}$ is not, of course, diagnostic of a primarily ventilatory of primarily perfusion basis for the increased mal distribution.

Changes in the $V_{D} / V_{T}$ ratio, which is frequently? a valuable index of ventilation-perfusion ratio mals distribution, were disappointingly small or neglio gible in most instances in the present study. Onê is obliged to conclude that, in the particular ciro cumstances, $\mathrm{A}-\mathrm{a} \mathrm{O}_{2}$ was a more sensitive index of change in ventilation-perfusion ratio distributiono

The differences in response of arterial $\mathrm{PO}_{2}$ and A-a $\mathrm{O}_{2}$ between different subjects may be of cons siderable significance. It has been shown in this laboratory that normal subjects differ reproduciblye. in the extent of their pulmonary vascular responses to hypoxia (Fowler and Read, 1963) and to exer cise (Read and Fowler, 1964); and it has beep suggested that normal subjects can be broadlyo divided into 'responders' and 'non-responders' a? far as pulmonary vascular reactivity is concernedo If this apparently intrinsic and reproducibl difference between individual normal subjects were carried over into disease states, one might expectr that some patients would show evidence of com? pensatory regional pulmonary vasoconstrictio $\mathbb{P}$ and that some would not. The present range o\$ responses would be consistent with such a hypoe 
thesis, 'responders' being those patients in whom $\mathrm{A}-\mathrm{a} \mathrm{O}_{2}$ increased after administration of the drugs.

In addition, the existence of regional compensatory vasoconstriction in the poorly ventilated regions of the lungs would move arterial blood gas tensions towards normal. One would expect 'responders' in general to have a higher arterial $\mathrm{Po}_{2}$ for a given degree of airways obstruction than non-responders. The data of Fig. 2 are again consistent with this section of the hypothesis. The patients showing a fall of $\mathrm{PO}_{2}$ and an increase of A-a $\mathrm{O}_{2}$ after receiving the drugs clearly had a higher mean initial $\mathrm{Po}_{2}$ than the other patients. Consideration of both mean and individual data showed that this was not simply due to their having higher initial F.E.V.$_{\cdot \cdot \cdot 0}$ levels. In the patients who received isoprenaline, the difference between initial $\mathrm{Po}_{2}$ in sub-group III subjects and those in sub-groups I and II was statistically highly significant (difference between means four times the standard error of the difference). In the patients who received aminophylline, the difference in initial mean $\mathrm{Po}_{2}$ between apparent 'responders' and apparent 'non-responders' was large and in the appropriate direction but did not achieve standard statistical levels of significance.

The therapeutic significance of the changes in arterial $\mathrm{Po}_{2}$ reported is difficult to assess. In no case was the fall in $\mathrm{Po}_{2}$ a dangerous one, but a decrease of arterial $\mathrm{Po}_{2}$ occurred in as many as one-third of the patients following the administration of these two widely used 'standard' bronchodilators. We re-emphasize that the patients in this study had chronic asthma rather than acute episodes and that we must be cautious in extrapolating the results to the more acute clinical situation. However, the present demonstration that a decrease of arterial $\mathrm{Po}_{2}$ following administration of these agents is not uncommon suggests that it is unwise to assume that they are free from danger when used in acute episodes. At low levels of arterial $\mathrm{Po}_{2}$ in severe acute asthma, any further decrease of $\mathrm{Po}_{2}$ may threaten life.

\section{REFERENCES}

Daly, J. J., and Howard, P. (1965). Effect of intravenous aminophylline on the arterial oxygen saturation in chronic bronchitis. Thorax, 20, 324.

Fowler, K. T., and Read, J. (1963). Effect of alveolar hypoxia on zonal distribution of pulmonary blood flow. J. appl. Physiol., 18, 244.

Halmagyi, D. F., and Cotes, J. E. (1959). Reduction in systemic blood oxygen as a result of procedures affecting the pulmonary circulation in patients with chronic pulmonary disease. Clin. Sci., 18,475 .

Needham, C. D., Rogan, M. C., and McDonald, I. (1954). Norma standards for hung volumes, intrapulmonary gas-mixing, and maximum breathing capacity. Thorax, 9, 313 .

Pain, M. C. F., Charlton, G., and Read, J. (1967). Effect of intravenous aminophylline on distribution of pulmonary blood flow in obstructive lung disease. Amer. Rev. resp. Dis., 95, 1005.

Read, J. (1958). Intrapuimonary gas mixing studied by the closed circuit helium technique. II. Normal and abnormal states in man. Aust. Ann. Med., 7, 187.

- and Fowler, K. T. (1964). Effect of exercise on zonal distribution of pulmonary blood flow. J. appl. Physiol., 19, 672 . 